\title{
Design of carborane molecular architectures with electronic structure computations: From endohedral and polyradical systems to multidimensional networks*
}

\author{
Josep M. Oliva ${ }^{1, \ddagger}$, Douglas J. Klein ${ }^{2}$, Paul von Ragué Schleyer ${ }^{3}$, and \\ Luis Serrano-Andrés ${ }^{4}$ \\ 1 "Rocasolano" Institute of Physical Chemistry, CSIC, ES-28006 Madrid, Spain; \\ ${ }^{2}$ Texas A\&M University at Galveston, Galveston, TX 77553-1675, USA; ${ }^{3}$ Center for \\ Computational Chemistry, University of Georgia, Athens, GA 30602, USA; \\ ${ }^{4}$ Institute of Molecular Science, University of València, ES-46071 València, Spain
}

\begin{abstract}
The 12 cage-anchoring points of the very stable icosahedral ortho-, meta-, and para-carborane allow the design of multidimensional architectures provided new self-assembling routes are devised. We provide bases for constructing carborane molecular architectures through high-level quantum chemical computations. We consider ejection mechanisms for the inner atom/ion in endohedral carborane complexes, singlet-triplet energy gaps in carborane biradicals, as well as geometry reorganization in carborane neutral and dianionic triplet states. These features, explored in monomers, are starting points for the design of molecular architectures based on electronic structure properties of carborane assemblies.
\end{abstract}

Keywords: carboranes; electronic structures; biradicals; DFT; CASSCF; CASPT2; dimers; singlet; triplet; dianions; molecular architecture; computational chemistry.

\section{INTRODUCTION}

The discoveries of carboranes [1] were first disclosed in the 1960s [2]; since then, many synthetic [3,4], spectroscopic [5], and computational investigations [3,6,7] have developed carborane chemistry into a mature field. The many applications include medicine [8-14], metal-ion extraction [15-17], nuclear fusion [18,19], nonlinear optics [20-23], homogeneous catalysis [24-26], liquid crystals [27-30], and others [31]. Experimental carborane chemistry has developed enormously in the last several decades. New carboranes have been synthesized with substituents in all 12 positions [32], supraicosahedral structures have been derived from carboranes [33], carborod or rigid-rod finite 1D polycarboranes (oligo- $p$ carboranes) [34,35], and recently supercluster systems based on icosahedral carborane clusters have been detected by ion-molecule reactions under ultra-high-vacuum conditions in a Penning trap [36]. Comprehensive reviews of carborane derivatives [3], vibrational spectra [5], and the electron distribution in closo-carboranes (polyhedral "closed" cages) extrapolated from electron distribution of $\mathrm{B}_{n} \mathrm{H}_{n}{ }^{2-}$ clusters [37] are available.

*Paper based on a presentation at the $19^{\text {th }}$ International Conference on Physical Organic Chemistry (ICPOC-19), 13-18 July 2008, Santiago de Compostela, Spain. Other presentations are published in this issue, pp. 571-776.

¥Corresponding author 
The possibility of controlling molecular properties by means of experimental cutting-edge techniques is at the heart of nanotechnology and biotechnology/medical research programs. Optical, magnetic, or electronic properties of molecules or clusters-predicted by means of electronic structure computations - can assist the development of polymolecular or nanoscopic devices designed with optimal predefined properties. A key point addressed in the present work is the possibility of using individual molecular/cluster properties of one unit along with pairs of coupled units (viewable as a $0 \mathrm{D}$ objects [38]) in the design of extended systems having more units and dimensions as obtained through the interconnection of various units into larger assemblies. To this end, carborane units, as stable building blocks, may be interconnected in different patterns; functional groups also may be attached. We have studied the electronic structure of finite assemblies of carborane molecules with icosahedral geometries built up into larger molecular architectures. Figure 1 shows the molecular geometry of 1,2-ortho-carborane, 1,7-meta-carborane, and 1,12-para-carborane with the IUPAC numbering of the cage atoms.

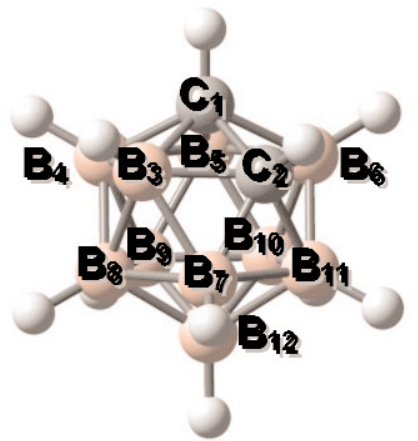

(a)

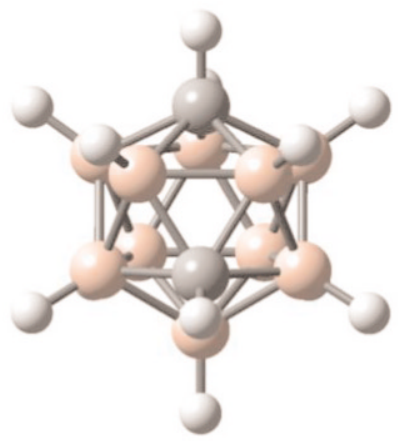

(b)

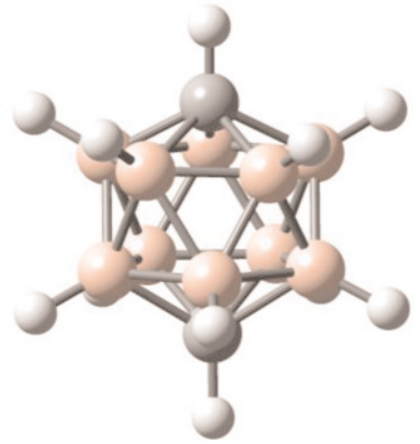

(c)

Fig. 1 Geometrical structure and IUPAC numbering of cage atoms in (a) ortho-carborane: $1,2-\mathrm{C}_{2} \mathrm{~B}_{10} \mathrm{H}_{12}$, (b) metacarborane: $1,7-\mathrm{C}_{2} \mathrm{~B}_{10} \mathrm{H}_{12}$ and (c) para-carborane: $1,12-\mathrm{C}_{2} \mathrm{~B}_{10} \mathrm{H}_{12}$. The point-group symmetries are $C_{2 \mathrm{v}}, C_{2 \mathrm{v}}$, and $D_{5 d}$, respectively. Atom numbering only is shown for ortho-carborane. The labels ortho, meta, and para resemble benzene analogs. Indeed, their chemistry has notable "aromatic" similarities $[2,3]$.

\section{CARBORANE MONOMERS: SUBSTITUTION EFFECTS, EXCITED STATES, ENDOHEDRAL COMPLEXES, AND BIRADICAL CHARACTER}

Our starting points for constructing model architectures, $o$-carborane, $m$-carborane, and $p$-carboranes (the "ortho-", "meta-" and "para-" prefixes are abbreviated, respectively) are studied first with regard to the electronic structure of (i) 1,2-disubstituted $o$-carboranes and their dianions in the ground state [7] and triplet excited states [39], (ii) endohedral carboranes [40,41], and (iii) carborane biradicals [42].

\section{1,2-Disubstituted o-carboranes and their dianions}

The properties of carborane clusters can be changed remarkably due to substituent effects $(\mathrm{R})$, charge $(q)$, spin $(S)$, and excited-state character $(\Psi)$ : summarized $\boldsymbol{P}=\boldsymbol{P}(\mathrm{R}, q, S, \Psi)$. Once these properties are well characterized (or deduced from quantum-mechanical computations), then assemblies of these 0D units can help predict how the properties evolve in (finite) 1D, 2D, and 3D networks: model-architectures explored in the research line presented here.

Figure 2 summarizes the computed $\mathrm{C} \cdots \mathrm{C}$ distances of 1,2-disubstituted octahedral 1,2- $\mathrm{R}_{2}-1,2-$ $\mathrm{C}_{2} \mathrm{~B}_{4} \mathrm{H}$ and icosahedral $o$-carboranes, $1,2-\mathrm{R}_{2}-1,2-\mathrm{C}_{2} \mathrm{~B}_{10} \mathrm{H}_{10}$ with $\mathrm{R}=\left(\mathrm{H}, \mathrm{CH}_{3}, \mathrm{NH}_{2}, \mathrm{OH}, \mathrm{F} ; \mathrm{SiH}_{3}, \mathrm{PH}_{2}\right.$, $\mathrm{SH}, \mathrm{Cl}$ ) in the singlet ground state [7]. 


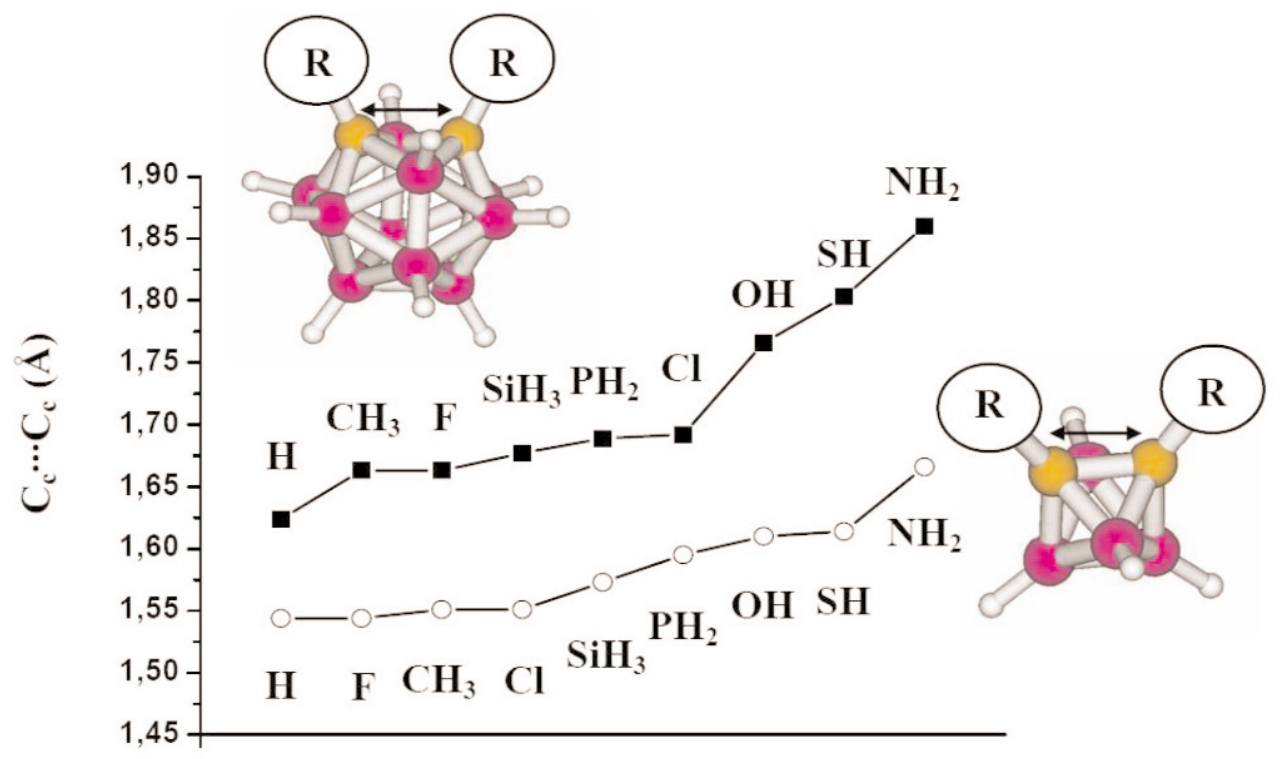

Fig. 2 C …C distances (in $\AA$ ) in disubstituted icosahedral $(n=10)$ and octahedral $(n=4) o$-carboranes $1,2-\mathrm{R}_{2}-1,2$ $\mathrm{C}_{2} \mathrm{~B}_{n} \mathrm{H}_{n}$. Computations with the B3LYP/6-31G* model.

The C ... C distance variation of icosahedral carboranes ranging from $1.624 \AA(\mathrm{R}=\mathrm{H})$ to $1.860 \AA$ $\left(\mathrm{R}=\mathrm{NH}_{2}\right)$ can be related to the electron donation from the highest occupied molecular orbital (HOMO) to the lowest unoccupied molecular orbital (LUMO) (the lone pairs from $\mathrm{R}=\mathrm{NH}_{2}$ have the greatest effect). The fluorine lone pairs are essentially inactive as donors: the HOMO plots for the $1,2-\mathrm{F}_{2}-1,2-$ $\mathrm{C}_{2} \mathrm{~B}_{10} \mathrm{H}_{10}$ cluster show no wave function amplitude in the $\mathrm{C}-\mathrm{C}$ bond region (see ref. [7] for details). The dianions derived from proton abstraction from both $\mathrm{R}$ groups [43] exhibit even larger $\mathrm{C} \cdots \mathrm{C}$ distance variations, from $1.823 \AA\left(\mathrm{R}^{-}=e^{-}\right)$to $2.638 \AA\left(\mathrm{R}^{-}=\mathrm{CH}_{2}^{-}\right)$. Thus, the variations of the cage $\mathrm{C} \cdots \mathrm{C}$ distances in neutral and dianionic 1,2-disubstituted $o$-carboranes are enormous (over $1 \AA$ )!

\section{Endohedral carborane complexes}

The first publication on buckminsterfullerene $\mathrm{C}_{60}$ [44] was followed by the discovery of endohedral fullerenes "M@cage" [45,46]. While the chemistry of endohedral fullerene has been developed extensively, this is not the case with endohedral boranes and carboranes. No syntheses or detection of icosahedral endohedral borane or carboranes have been reported. We have performed the first electronic structure computations on such compounds $[47,48]$ by considering the stabilities and geometries of exohedral (X‥cage) and endohedral (X@cage) icosahedral carboranes derived from $o$-carborane, $m$-carborane, $p$-carborane, the monoanion $\mathrm{CB}_{11} \mathrm{H}_{12}$, and the cations $\mathrm{X}=\left(\mathrm{Li}^{+}, \mathrm{Be}^{2+}\right)$. [41]. Recently, we provided theoretical evidence that a photochemical window mechanism may exist for the release of the inner metal atom in the endohedral $\mathrm{Li} @ \mathrm{CB}_{11} \mathrm{H}_{12}$ carborane upon absorption of light (see Fig. 3) [49]. The presence of a related window mechanism in the triplet state of $\mathrm{C}_{60}$ was reported in pioneering theoretical studies [50]. 


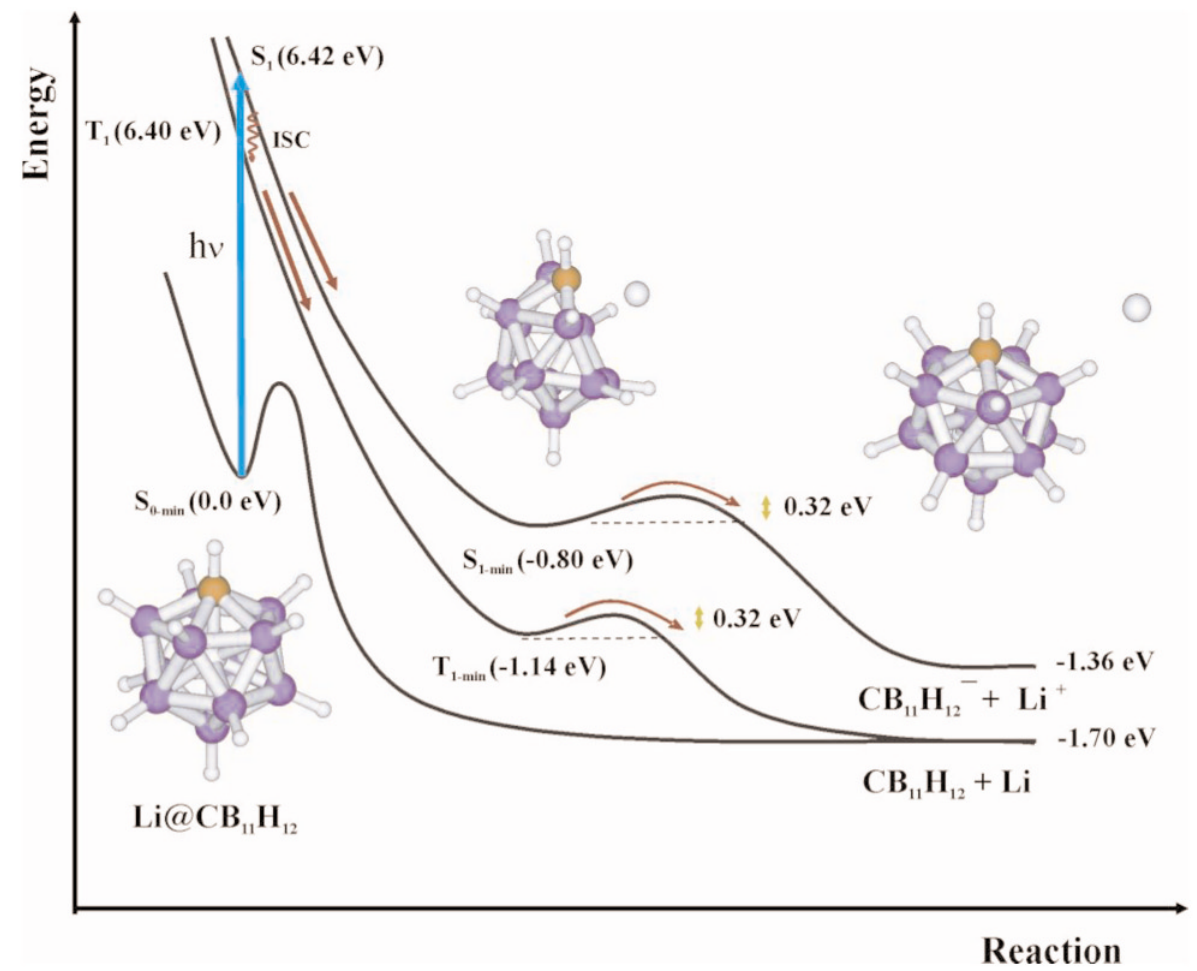

Fig. 3 Photochemical evolution of the endohedral Li@ $\mathrm{CB}_{11} \mathrm{H}_{12}$ carborane complex upon irradiation leads to a selective release of the inner atom. The scheme is based on quantum chemical DFT/B3LYP and CASPT2//CASSCF computations. Energy: potential energy. ISC: intersystem crossing [49]. Reprinted with permission from Elsevier, copyright (2006).

\section{Carborane monoradicals and biradicals: Excited states}

The experimental information regarding structural or spectroscopic properties of monoradicals, biradicals, and excited states derived from the three icosahedral carborane isomers, is limited to the synthesis (and crystal structure) of the permethylated carborane radical $\mathrm{CB}_{11}\left(\mathrm{CH}_{3}\right)_{12}{ }^{\bullet}$ [51], the photochemistry of the $\mathrm{CB}_{11} \mathrm{H}_{12}{ }^{-}$anion [52], and more recently the synthesis of the biradical ${ }^{\bullet}\left[\left(\mathrm{CH}_{3}\right)_{11} \mathrm{CB}_{11}\right]$ bridge- $\left[\mathrm{CB}_{11}\left(\mathrm{CH}_{3}\right)_{11}\right]^{\bullet}$ where the bridge is $-\mathrm{C} \equiv \mathrm{C}-$ or $-\mathrm{CH}_{2}=\mathrm{CH}_{2}-$ [53]. No thermochemical data is available, to our knowledge, on the bond dissociation energies (BDEs) for carborane clusters (as in eq. 1) or radicals (as in eq. 2)

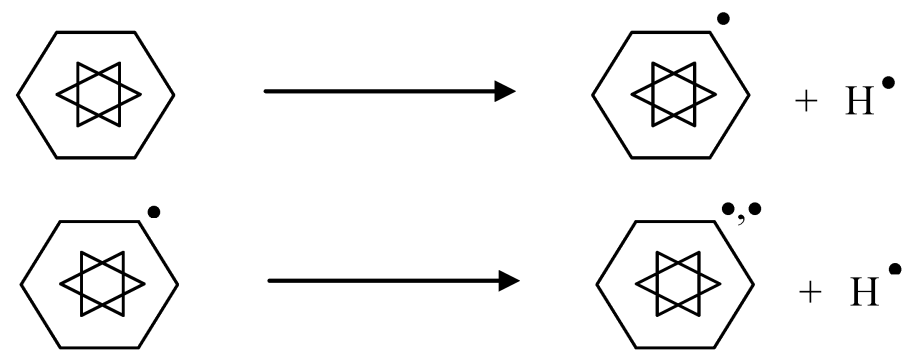

where the hexagon with the star inside symbolizes any of the three icosahedral carborane isomers. Thus, we computed structures, relative stabilities, singlet-triplet gaps, and the ground-state character of mono- 
and biradicals derived from the three icosahedral carborane cage isomers, as well as BDEs for eqs. 1 and 2 [42]. The methodology involved calibration of unrestricted broken-symmetry density functional theory (DFT) with CASPT2 results (especially for the adiabatic singlet-triplet energy gaps). The BDE for carboranes is close to the benzene $\mathrm{BDE}\left[D_{0}(\mathrm{expt})=112.4 \mathrm{kcal} / \mathrm{mol}, D_{0}\left(\mathrm{~B} 3 \mathrm{LYP} / 6-31 \mathrm{G}^{*}\right)=118.1\right.$ $\mathrm{kcal} / \mathrm{mol}$ ], within $\pm 3 \mathrm{kcal} / \mathrm{mol}$ (eq. 1); the energy window for the BDEs of carborane radicals is an order of magnitude larger (eq. 2 and Fig. 4). Interestingly, all monomeric carborane biradicals have singlet ground states. However, the triplet states of some of the species are assessable, with adiabatic singlettriplet energy gaps close to $k_{\mathrm{B}} \cdot T$ and offer the potential of building biradical multidimensional carborane network architectures with predesigned magnetic properties and consequent potential applications to quantum computing and high-density information storage [54,55]. Figure 4 gathers the computed
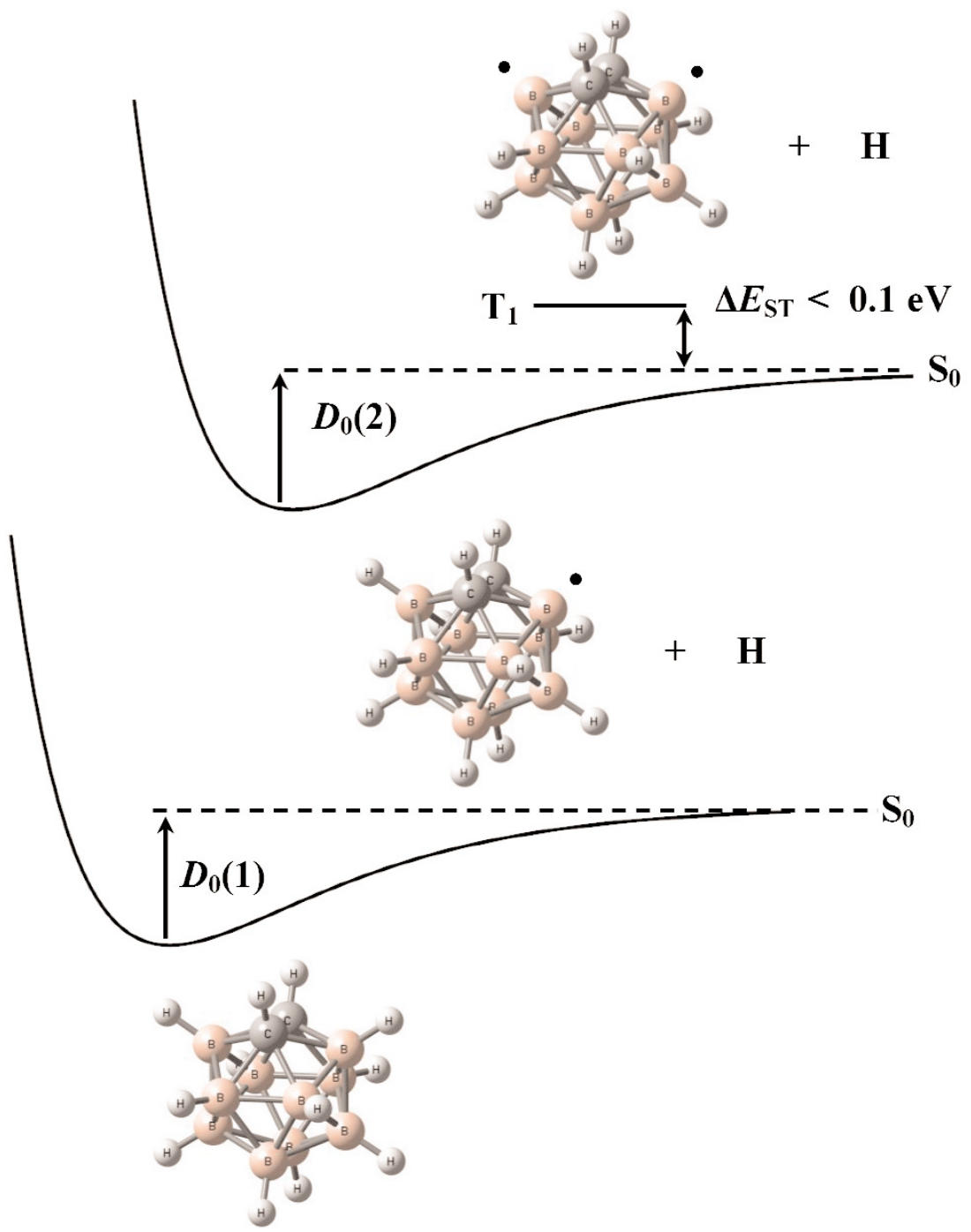

Fig. 4 Energy profiles for eq. 1 (bottom) and eq. 2 (top) in the particular case of the biradical $o$ - $(3,6)$. Hydrogen abstraction on position (3) in $o$-carborane leads to monoradical $o$-(3), with a $D_{0}(1)=108.2 \mathrm{kcal} / \mathrm{mol}$ (UB3LYP/6$\left.31 \mathrm{G}^{*}\right)$, bottom curve. A second hydrogen abstraction on position $(6)$ top, leads to $o$-carborane biradical $o$ - $(3,6)$ with a computed adiabatic singlet-triplet energy gap of $\Delta E_{\mathrm{ST}}=0.06 \mathrm{eV}$ (CASPT2//CASSCF/6-31G*). $D_{0}(2)=101.6$ $\mathrm{kcal} / \mathrm{mol}$ (unrestricted broken-symmetry UB3LYP/6-31G*). 
BDEs for $o$-carborane when hydrogen abstraction takes place on positions (3) and (6) consecutivelyeqs. 1 and 2 above. The computed adiabatic singlet-triplet energy gap is close to $k_{\mathrm{B}} \cdot T$ at room temperature. Thus, the field of carborane excited states only started recently. A computational study of the triplet states of 1,2-disubstituted $o$-carborane and their dianions [39] followed the examination of the ground-state systems mentioned above.

\section{CARBORANE DIMERS: ENDOHEDRAL COMPLEXES}

The ability to elucidate electronic structures computationally enables the design of carborane cluster assemblies with desired properties. This, in turn, might lead to the development of new synthetic methods for joining carborane units in different dimensions, a nontrivial experimental task.

For example, the endohedral carboranes described above might be joined in order to obtain unusual or enhanced properties. Thus, the combination of endohedral with normal clusters can give highly orientable dimers due to their very high dipole moments (Fig. 5).

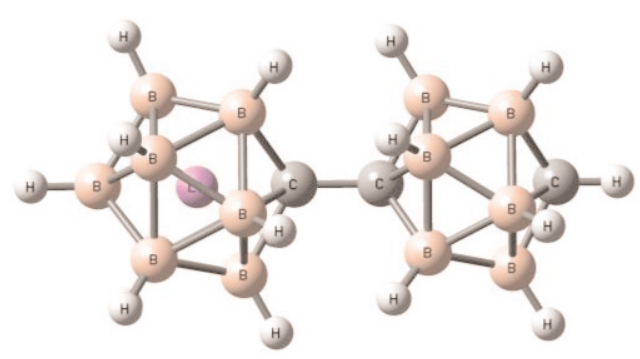

$\mu=2.9 \mathrm{D}, \quad E=-657.15514 \mathrm{au}$

(a)

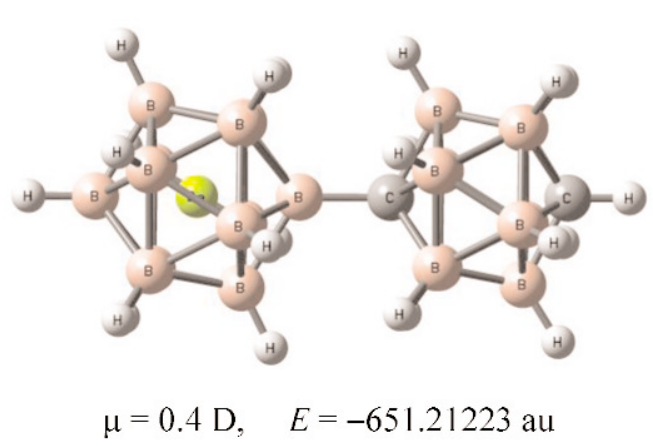

(c)

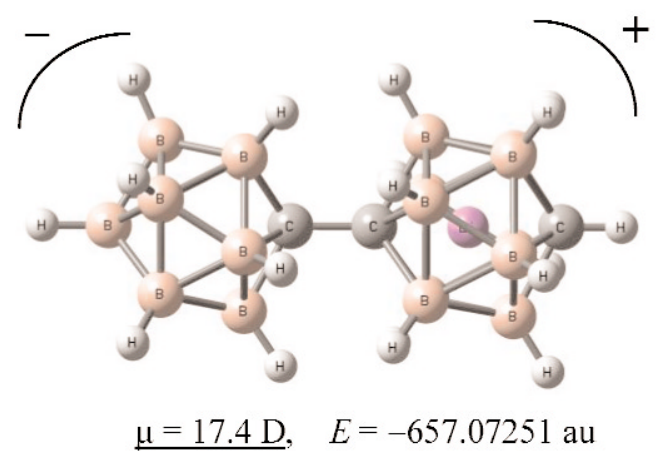

(b)

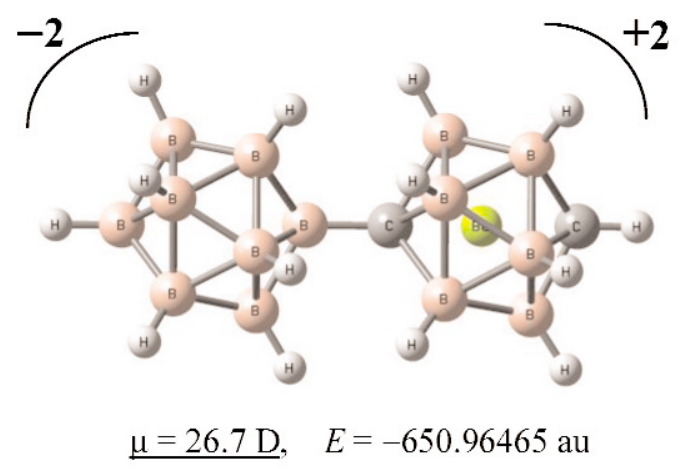

(d)

Fig. 5 Dimeric carborane systems combining neutral $p$-carborane and $\mathrm{CB}_{11} \mathrm{H}_{12}{ }^{-}$or $\mathrm{B}_{12} \mathrm{H}_{12}{ }^{-2}$ units, connected by $\mathrm{C}-\mathrm{C}$ and $\mathrm{C}-\mathrm{B}$ bonds, respectively. Dipole moments (in Debye) and energies (in atomic units) computed at the B3LYP/6-31G* level. (a) $\left\{\mathrm{Li} @ \mathrm{CB}_{11} \mathrm{H}_{11}\right\}-\left\{p-\mathrm{C}_{2} \mathrm{~B}_{10} \mathrm{H}_{11}\right\}$, (b) $\left\{\mathrm{CB}_{11} \mathrm{H}_{11}\right\}-\left\{\mathrm{Li} @ p-\mathrm{C}_{2} \mathrm{~B}_{10} \mathrm{H}_{11}\right\}$, (c) $\left\{\mathrm{Be} @ \mathrm{~B}_{12} \mathrm{H}_{11}\right\}-$ $\left\{p-\mathrm{C}_{2} \mathrm{~B}_{10} \mathrm{H}_{11}\right\}$, (d) $\left\{\mathrm{B}_{12} \mathrm{H}_{11}\right\}-\left\{\mathrm{Be} @ p-\mathrm{C}_{2} \mathrm{~B}_{10} \mathrm{H}_{11}\right\}$. 
The giant dipole moments of the Figs. $5 \mathrm{~b}$ and $5 \mathrm{~d}$ dimers are comparable to those measured in organic molecules with $\sim 20 \AA$ donor and acceptor site separations [56]. In contrast, the distance between the icosahedral centers in Figs. $5 \mathrm{~b}$ and $5 \mathrm{~d}$ is only $\sim 5 \AA$. This demonstrates that very large dipole moments can be obtained in smaller systems, which would then be highly orientable in electric fields (e.g., for building "molecular-based" condensers).

\section{HIGHER-ORDER ARCHITECTURES}

Larger assemblies in different dimensions also can be designed by joining carborane units and their structures and properties predicted by electronic structure computations. Thus, endohedral or (poly)radical units might elaborate the 1D carborane rods with a finite number of units synthesized more than a decade ago [34,35] in order to introduce, enhance, or define a desired property (e.g., small/large singlet-triplet gaps, small/large dipole moments, etc.).

The carborane hexamer shown in Fig. 6 illustrates such a higher architectural construct.

Irradiation of the hexameric supercluster shown in Fig. 6 might eject a $\mathrm{Li}$-atom or a $\mathrm{Li}^{+}$cation (via mechanisms like that in Fig. 3) depending on the photon energy. This circular unit might also be incorporated in a larger supercluster as a charged unit.

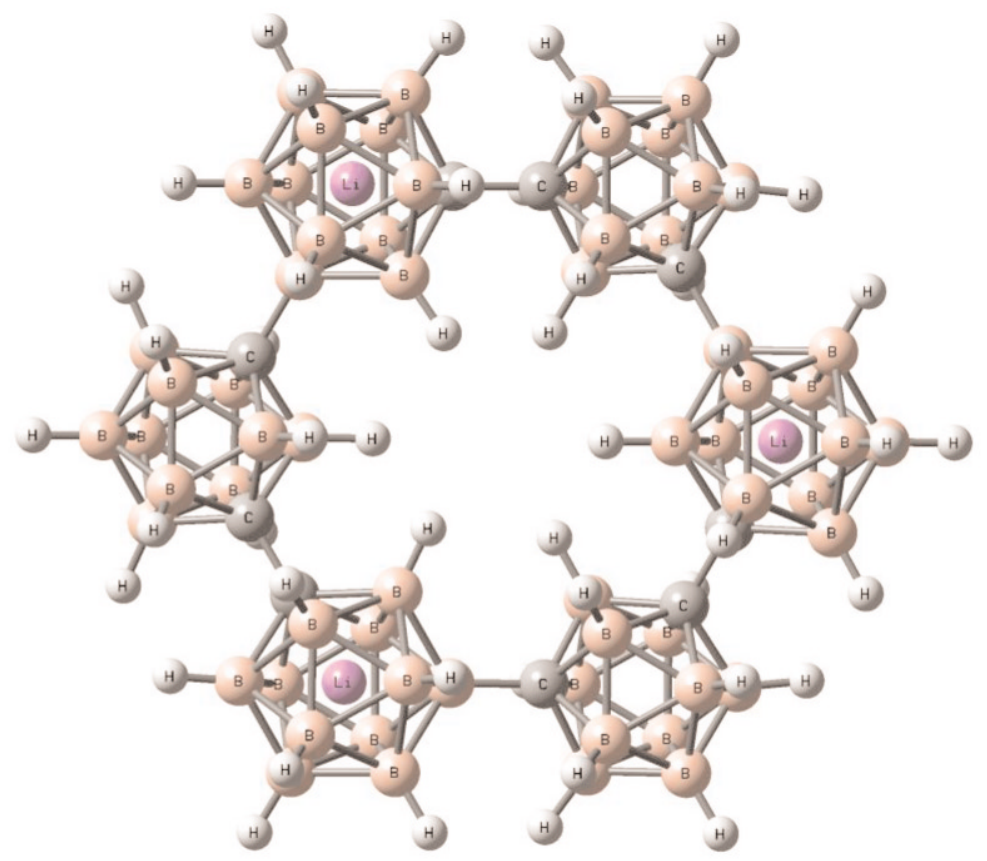

Fig. 6 The B3LYP/6-31G* optimized geometry of a neutral, cyclic carborane hexamer with alternating endohedral $\mathrm{Li} @ \mathrm{CB}_{11} \mathrm{H}_{12}$ and $m$-carboranes connected through $\mathrm{C}-\mathrm{C}$ and $\mathrm{C}-\mathrm{B}$ bonds.

\section{CONCLUSIONS}

We have reported computations on the electronic structure of substituted, endohedral, and joined carborane clusters. Various molecular architectures can be designed to introduce or enhance desired properties. Examples include the combinations of atoms, ions, or molecules with carborane clusters and superclusters leading to exohedral and endohedral complexes, which allow the modeling of excited states with various energy gaps from the ground state. 
Notably, the coupling between the unpaired electrons at various positions of the carborane biradicals can be substantial, regardless of their relative positions in the carborane. A diverse array of novel nanostructures can be built by linking the carborane units; the endohedral species and appended radical sites offer additional possibilities for different designs.

Knowledge of a single unit and of a coupled pair of units via ab initio electronic-structure computations can be utilized in systematic expansions to estimate properties in extended (even infinite) 1D, 2D, and 3D systems. A scalar property may be directly "cluster expanded" via "group additivity" or "group function" [57-59] schemes.

Such essentially classical approaches are best applicable to extensive properties with closed-shell units. However, in large open-shell systems, where different locally open-shell subunits are coupled, many properties (e.g., magnetic susceptibilities or electronic conductivities) are often sensitive to correlations among the different subunits. Indeed, when the resultant eigenstates are coupled weakly, the global wave-function obtained by coupling the local functions can lie close together energetically, while also differing greatly (in terms of the subunit correlations), so that associated properties can change dramatically with temperature.

Consequently, more sophisticated extrapolative schemes are appropriate, by way of a (somewhat parallel) cluster expansion of the effective many-body Hamiltonian, say of generalized Heisenberg, Hubbard, or Pariser-Parr-Pople types (e.g., [60-63]), where higher-order approximations may require quantum-chemical input computations beyond just a pair of subunits. Even when limited to interactions between pairs of units, such effective Hamiltonians allow for various collective or cooperative effects (such as spontaneous magnetization and temperature-dependent properties) for the various nanostructures we considered. The solutions of such effective quantum-mechanical Hamiltonians are complicated, but may be enabled by powerful general techniques, including: systematic extrapolations of brute-force configuration-interaction computations [64,65], quantum Monte Carlo estimates [66], wave-function cluster expansion methods [67-69], different many-body perturbation-theoretic expansions [70-72], density-matrix renormalization-group estimates [73,74], and others [75].

Our computations not only apply quantitatively to the small systems considered, but also provide the basis for a broader study as well as the understanding of the diverse range of nanostructures that may be built up from individual carborane units.

\section{ACKNOWLEDGMENTS}

This work is dedicated to the memory of Luis Condal Bosch (1925-2005), former Professor of Chemical Physics at the Institut Químic de Sarrià (Universitat Ramon Llull, Barcelona). The authors acknowledge support from Spanish projects MAT2006-13646-C03-02 (JMO), CTQ2007-61260, and CSD2007-0010 Consolider-Ingenio in Molecular Nanoscience of the Spanish MEC/FEDER (LS-A), National Science Foundation Grant CHE-0716718 (PvRS), and grant BD-0894 from the Welch Foundation of Houston, Texas (DJK). Prof. Luis Garay (UCM, Spain) is acknowledged for discussing with us this work. We are also indebted to Prof. Ll. Victori (IQS-URL, Barcelona) for reading the manuscript.

\section{REFERENCES AND NOTES}

1. Clusters of atoms including hydrogen, boron, and carbon: in this work we include clusters of atoms $\mathrm{C}_{x} \mathrm{~B}_{y} \mathrm{H}_{z}$ with (quasi) icosahedral symmetry.

2. R. N. Grimes. Carboranes, Academic Press, New York (1970).

3. J. Casanova. The Borane, Carborane, Carbocation Continuum, John Wiley, New York (1998).

4. V. I. Bregadze. Chem. Rev. 92, 209 (1992).

5. L. A. Leites. Chem. Rev. 92, 279 (1992). 
6. I. V. Glukhov, K. A. Lyssenko, A. A. Korlyukov, M. Y. Antipin. Faraday Discuss. 135, 203 (2007).

7. J. M. Oliva, N. L. Allan, P. v. R. Schleyer, C. Viñas, F. Teixidor. J. Am. Chem. Soc. 127, 13538 (2005).

8. G. Brownell, R. G. Zamenhof, B. W. Murray, G. R. Wellum. "Boron neutron capture therapy", in Therapy in Nuclear Medicine, R. P. Spencer (Ed.), Grune and Stratton, New York (1978).

9. M. F. Hawthorne, A. Maderna. Chem. Rev. 99, 3421 (1999).

10. A. H. Soloway, W. Tjarks, A. Barnum, F.-G. Rong, R. F. Barth, I. M. Codogni, J. G. Wilson. Chem. Rev. 98, 1515 (1998).

11. J. F. Valliant, K. J. Guenther, A. S. King, P. Morel, P. Schaffer, O. O. Sogbein, K. A. Stephenson. Coord. Chem. Rev. 232, 173 (2002).

12. M. F. Hawthorne, M. W. Lee. J. Neuro-Oncol. 62, 33 (2003).

13. I. B. Sivaev, V. I. Bregadze, N. T. Kuznetsov. Russ. Chem. Bull., Int. Ed. 51, 1362 (2002).

14. W. Tjarks. J. Organomet. Chem. 37, 614 (2000).

15. J. Plesek. Chem. Rev. 92, 269 (1992).

16. N. Zine, J. Bausells, A. Ivorra, J. Aguilo, M. Zabala, F. Teixidor, C. Masalles, C. Vinas, A. Errachid. Sens. Actuators, B 91, 76 (2003).

17. B. Grüner, J. Plesek, J. Baca, I. Cisarova, J.-F. Dozol, H. Roquette, C Viñas, P. Selucky, J. Rais. New J. Chem. 26, 1519 (2002).

18. O. I. Buzhinsky, V. G. Ostroshchenko, D. G. Whyte, M. Baldwin, R. W. Conn, R. P. Doerner, R. Seraydarian, S. Luckhardt, H. Kugel, W. P. West. J. Nucl. Mater. 313, 214 (2003)

19. D. Tafalla, F. L. Tabares. Vacuum 67, 393 (2002).

20. Chem. Rev. 94 (1994), special issue, and references therein.

21. P. R. Prasad, D. J. Williams. Introduction to Nonlinear Optical Effects in Molecules and Polymers, John Wiley, New York (1991).

22. R. Hamasaki, M. Ito, M. Lamrani, M. Mitsuishi, T. Myashita, Y. Yamamoto. J. Mater. Chem. 13, 21 (2003).

23. F. Fabrizi di Biani, M. Fontani, E. Ruiz, P. Zanello, J. M. Russell, R. N. Grimes. Organometallics 21, 4129 (2002).

24. D.-H. Kim, J. H. Won, S.-J. Kim, J. Ko, S. H. Kim, S. Cho, S. O. Kang. Organometallics 20, 4298 (2001).

25. C. De Rosa, P. Corradini, A. Buono, F. Auriemma, A. Grassi, P. Altamura. Macromolecules 36, 3789 (2003)

26. H. Shen, H. S. Chan, Z. W. Xie. Organometallics 27, 5309 (2008).

27. P. J. Collings. Liquid Crystals, $2^{\text {nd }}$ ed., Princeton University Press, Princeton, NJ (2001).

28. E. Bakker, P. Buhlmann, E. Pretsch. Chem. Rev. 97, 3083 (1997).

29. S. Peper, Y. Qin, P. Almond, M. McKee, M. Telting-Diaz, T. Albrecht-Schmitt, E. Bakker. Anal. Chem. 75, 2131 (2003).

30. M. Krondak, R. Volf, V. Kral. Collect. Czech. Chem. Commun. 66, 1659 (2001).

31. J. de Zeeuv, J. Luong. Trends Anal. Chem. 21, 594 (2002).

32. F. Teixidor, C. Viñas, A. Demonceau, R. Nuñez. Pure Appl. Chem. 75, 1305 (2003).

33. D. Ellis, R. D. McIntosh, S. Esquirolea, C. Viñas, G. M. Rosair, F. Teixidor, A. J. Welch. Dalton Trans. 1009 (2008).

34. W. Jiang. D. E. Harwell, M. D. Mortimer, C. B. Knobler, M. F. Hawthorne. Inorg. Chem. 35, 4355 (1996).

35. J. Müller, K. Baše, T. F. Magnera, J. Michl. J. Am. Chem. Soc. 114, 9721 (1992).

36. H. Hiura, T. Kanayama. J. Mol. Struct. 735-736, 367 (2005).

37. R. E. Williams. Chem. Rev. 92,177 (1992). 
38. The consideration of a molecule or cluster as a $0 \mathrm{D}$ object allows the viewing of the whole multidimensional architecture as a set of $N$ "points" (each corresponding to one of our units) in different dimensions (0D, 1D, 2D, or 3D) that have single-unit (optical, magnetic or electronic) properties and lead through appropriate interaction estimated from the computation for a pair of units to a "global" property.

39. J. M. Oliva, L. Serrano-Andrés. J. Comput. Chem. 27, 524 (2006).

40. V. Manero, J. M. Oliva, L. Serrano-Andrés, D. J. Klein. J. Chem. Theory Comput. 3, 1399 (2007).

41. J. I. Burgos, L. Serrano-Andrés, J. M. Oliva, D. J. Klein. Afinidad 533, 32 (2008).

42. L .Serrano-Andrés, D. J. Klein, P. v. R. Schleyer, J. M. Oliva. J. Chem. Theory Comput. 4, 1338 (2008).

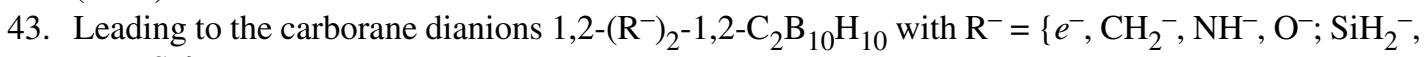
$\mathrm{PH}^{-}, \mathrm{S}^{-}$.

44. H. W. Kroto, J. R. Heath, S. C. O’Brien, R. F. Curl, R. E. Smalley. Nature 318, 162 (1985).

45. Y. H. Hu, E. J. Ruckenstein. J. Am. Chem. Soc. 127, 11277 (2005).

46. L. Liu, B. Gao, W. Chu, D. Chen, T. Hu, C. Wang, L. Dunsch, A. Marcelli, Y. Luo, Z. Wu. Chem. Commun. 474 (2008).

47. E. D. Jemmis, M. M. Balakrishnarajan. J. Am. Chem. Soc. 122, 7392 (2000).

48. O. P. Charkin, N. M. Klimenko, D. Moran, A. M. Mebel, D. O. Charkin, P. v. R. Schleyer. J. Phys. Chem. A 106, 11594 (2002).

49. L. Serrano-Andrés, J. M. Oliva. Chem. Phys. Lett. 432, 235 (2006).

50. R. L. Murry, G. E. Scuseria. Science 263, 791 (1994).

51. B. T. King, B. C. Noll, A. J. McKinley, J. Michl. J. Am. Chem. Soc. 118, 10902 (1996).

52. F. X. L. Xamena, L. Teruel, M. S. Galletero, A. Corma, H. García. Chem. Commun. 499 (2008).

53. J. Eriksson, K. Vyakaranam, J. Ludvík, J. Michl. J. Org. Chem. 72, 2351 (2007).

54. M. Cavallini, M. Facchini, C. Albonetti, F. Biscarini. Phys. Chem. Chem. Phys. 10, 784 (2008).

55. R. Wasser (Ed.). Nanoelectronics and Information Technology, John Wiley, Weinheim (2003).

56. S. N. Smirnov, C. L. Braun, S. R. Greenfield, W. A. Svec, M. R. Wasiliewski. J. Phys. Chem. 100, 12329 (1996).

57. V. M. Tateavskii, V. A. Benderskii, S. S. Yarovoi. Rules and Methods for Calculating the PhysicoChemical Properties of Paraffinic Hydrocarbons, (English translation) Pergamon Press, Oxford (1961).

58. J. D. Cox, Pilcher. Thermochemisty of Organic and Organometallic Compounds, Academic Press, New York (1970).

59. S. W. Benson. Thermochemical Kinetics, John Wiley, New York (1976).

60. R. D. Poshusta, D. J. Klein. Phys. Rev. Lett. 48, 1555 (1982).

61. J. P. Malrieu, D. Maynau, J. P. Daudey. Phys. Rev. B 38 (1984) 1817.

62. N. Guihery, N. B. Amor, D. Maynau, J. P. Malrieu. J. Chem. Phys. 104, 3701 (1996).

63. J. Wu, T. G. Schmalz, D. J. Klein. J. Chem. Phys. 117, 9977 (2002).

64. J. C. Bonner, M. E. Fisher. Phys. Rev. A 135, 640 (1964).

65. S. R. White, R. M. Noack, D. J. Scalapino. Phys. Rev. Lett. 73, 886 (1994).

66. S. Liang, N. Doucet, P. W. Anderson. Phys. Rev. Lett. 61, 365 (1988).

67. D. J. Klein, M. A. Garcia-Bach. Phys. Rev. B 19, 877 (1979).

68. F. E. Harris. Phys. Rev. B 47, 7903 (1993).

69. R. F. Bishop, J. B. Parkinson, Y. Xian. Phys. Rev. B 44, 9425 (1991).

70. J. Cioslowski. Phys. Rev. 36, 374 (1987).

71. J. Oitmaa, C. J. Hamer, Z. Weihong. Phys. Rev. B 45, 9834 (1992).

72. J. Wang. Phys. Rev. B 45, 2282 (1992).

73. S. R. White. Phys. Rev. Lett. 69, 2863 (1992).

74. F. Verstraete, J. I. Cirac. arXiv:cond-mat/0407066v1 
75. P. W. Anderson. The Theory of Superconductivity in the High- $T_{c}$ Cuprates, Princeton University Press, Princeton, NJ (1997).

76. R. B. King. Russ. Chem. Bull. 42, 1283 (1993).

(C) 2009 IUPAC, Pure and Applied Chemistry 81, 719-729 